\title{
A atuação do cinema intercultural nos imaginários de naturalização da violência contra imigrantes
}

The role of intercultural cinema in the imagery of naturalization of violence against immigrants

El papel del cine intercultural en los imaginarios de naturalización de la violencia contra inmigrantes

Célia Maria Retz Godoy dos Santos

- Doutora em Sociologia

- Mestre em Comunicação

- Publicou mais de 130 trabalhos em anais de eventos nacionais e internacionais, com pesquisas nas áreas de relações públicas, comunicação, participação política e opinião pública

- Coordenadora do curso de pós-graduação lato sensu em Estratégias competitivas: comunicação, inovação e liderança da Universidade Estadual Paulista (Unesp)

- Docente regular do Programa de Pós-Graduação em Mídia e Tecnologia da Unesp.

- E-mail: celia.retz@unesp.br

\section{André Aparecido Medeiros}

- Mestre em Comunicação pela Universidade Estadual Paulista (Unesp)

- Possui experiência em diferentes áreas do audiovisual e em pesquisa, com destaque para comunicação, relações de poder, paz e interculturalidade

- Possui artigos em eventos científicos, revistas e jornais

- Roteirizou e dirigiu quatro curtas, com participação em festivais

- Participou da comissão de mídia do Fórum Social Mundial das Migrações (2016)

- E-mail: andreapmed@hotmail.com 


\section{Resumo}

Comunicadores, incluindo cineastas, nem sempre usam a mídia em prol da interculturalidade e da paz. Certas abordagens são exemplos de violência cultural e são usadas de modo a justificar outras formas de violência, repercutindo sobre imigrantes. Por meio da pesquisa bibliográfica é possível notar que, em oposição a isso, o cinema intercultural contribui descontruindo imaginários que tentam "naturalizar" a violência contra a pessoa imigrante e construindo novos imaginários sociais.

PALAVRAS-CHAVE: CINEMA INTERCULTURAL •COMUNICAÇÃO PARA A PAZ •VIOLÊNCIA ESTRUTURAL・VIOLÊNCIA CULTURAL・MIGRAÇÃO.

\section{Abstract}

Communicators, including filmmakers, do not always use media to promote interculturality and peace. Certain approaches are examples of cultural violenceand are used to justify other forms of violence, affecting immigrants. Through bibliographical research, it is possible to note that, opposed to this, intercultural cinema contributes by deconstructing imaginaries that try to "naturalize" violence against immigrant person and by building new social imaginaries.

KEYWORDS: INTERCULTURAL CINEMA•COMMUNICATION FOR PEACE•STRUCTURAL VIOLENCE • CULTURAL VIOLENCE• MIGRATION.

\section{Resumen}

Los comunicadores, incluidos los cineastas, no siempre utilizan los medios para la interculturalidad y la paz. Algunos enfoques son ejemplos de violencia cultural y se utilizan para justificar otras formas de violencia, repercutiendo sobre los inmigrantes. Por medio de la investigación bibliográfica se nota que, en oposición a eso, el cine intercultural contribuye deconstruyendo imaginarios que intentan "naturalizar" la violencia contra la persona inmigrante y construyendo nuevos imaginarios sociales.

PALABRAS CLAVE: CINE INTERCULTURAL・COMUNICACIÓN PARA LA PAZ•VIOLENCIA ESTRUCTURAL・VIOLENCIA CULTURAL・MIGRACIÓN. 
ANO 15 • NÚMERO 28 • 1ํㅗㅌ. 2018 • ORGANICOM

\section{INTRODUÇÃO}

0 predomínio da fala de cidadãos autóctones na indústria cultural confere espaço para a divulgação de um número significativo de conteúdos limitados, produzidos por profissionais descompromissados ou que nem sempre refletiram acerca das questões interculturais. No caso do cinema, por vezes, os filmes são preconceituosos, embasados em estereótipos, com direcionamento específico para os grupos dominantes, contribuindo para a perpetuação da sua supremacia ideológica.

De modo geral, a violência não parte apenas de pessoas físicas, podendo também ser provocada por instituições e manifestações culturais, repercutindo em preconceito, medo e desigualdades. Seja diretamente na sociedade ou em sua representação, três formas principais de violência podem ser identificadas, conforme classificação de Galtung (2005): direta, estrutural (ou sistêmica) e cultural.

A violência direta é mais fácil de ser vista, tradicionalmente, como violência, pois nela são facilmente reconhecidos o agressor e a vítima. Conforme Diskin (2007, p. 10), ela ocorre com o "uso da força (ou ameaça de uso de força), da palavra e do gesto com o intuito de provocar sofrimento, humilhação, desqualificação ou simplesmente eliminação do outro". Causa uma privação imediata da vida ou da integridade física, podendo ser exemplificada nas guerras, no genocídio, na violência doméstica, em brigas etc. Sua ausência compreende a paz direta ou paz negativa. No cinema, ela aparece na representação: de ameaça, de exposição a um risco (negligência), de agressão verbal ou física.

A violência estrutural ou sistêmica apresenta, de acordo com Galtung (2005, p. 63), a presença de "mecanismos sistêmicos de injustiça e morte". Nela podem ser identificadas as vítimas, mas os agressores não são identificados diretamente. Ela "se constrói em um sistema social e [...] se expressa pela desigualdade de oportunidades, de acesso às necessidades básicas, tais como educação, saúde, alimentação, moradia digna, trabalho, cultura e lazer" (Diskin, 2007, p. 10). Provoca a privação lenta da vida ou da qualidade de vida, de modo a ser exemplificada nas más condições de sobrevivência. Em contraposição à violência estrutural está a paz positiva (ou paz estrutural, conforme definiu Galtung (2005)), tipo de paz na qual, além da ausência de violência direta, estão presentes a justiça e o desenvolvimento, com as necessidades humanas básicas satisfeitas. Essa violência é abordada, nos filmes, na representação da privação dos direitos humanos e, assim, no prejuízo ao bem-estar social.

A "produção de ideias justificadas das demais violências" (Galtung, 2005, p. 63) gera outro tipo de violência: a violência cultural. Ela "alude a peculiaridades da cultura/comunicação/etnia para justificar ou legitimar o uso direto, simbólico ou estrutural da violência" (Diskin, 2007, p. 10). Na violência cultural, agressores e vítimas são de difícil identificação imediata. Ela é representada nas situações em que a violência apresenta um fundo cultural ou ideológico.

É importante considerar que, constituindo um produto da cultura, o filme, em si, repercute como um modelo de violência ou de paz. As artes, as ciências, as religiões e tudo aquilo que produza cultura, incluindo a comunicação, pode legitimar a violência ou a paz, de modo que a paz cultural é a alternativa diante da violência cultural. Em face às suas características, ela é um importante ideal de paz, pois, com a difusão de uma cultura de paz, a paz estrutural e a paz direta florescerão de modo mais propício. Nessa circunstância, a comunicação, ao construir e destruir realidades, pode ser boa ou ruim, violenta ou pacífica, conforme seus princípios ou intenções. 
Ainda que a recepção de um produto cultural seja um fenômeno individual, a construção de qualquer filme apresenta elementos com potencial de conduzir a percepção do público. Ao encontro desse fato, o uso gratuito da violência no cinema não gera, necessariamente, a conscientização acerca de sua presença na sociedade e da necessidade de efetivação de seu combate. Em um filme, empatias, antipatias e indiferenças podem ser trabalhadas, trazendo ganhos ou prejuízos às populações, conforme diferentes fenômenos de gravidade social sejam banalizados ou adequadamente endossados e conforme 0 impacto que isso desperte nos distintos públicos.

Atuando na construção e na consolidação de imaginários, o cinema, ao representar a violência, exerce um papel social que pode repercutir nas referências de percepção e mesmo de tratamento a diversos grupos. Por meio do cinema, o contato e o conhecimento acerca do outro pode ser ampliado ou restringido. Na busca pelo ganho financeiro e pelo alcance de determinados interesses políticos, por vezes, as causas humanitárias e as necessidades de grupos diretamente relacionados a essas abordagens não recebem a devida importância. Com isso, muitas vezes, a representação da violência, no lugar de despertar a reflexão que propulsione a paz, apenas reforça e justifica a violência já existente.

O jogo político e econômico das nações interfere na sociedade e gera exploradores e explorados, em um processo de violência estrutural e cultural. Apesar do reconhecimento do sofrimento, as ideias são, por vezes, culturalmente justificadas ou aceitas. A violência estrutural, estando nos sistemas, também se apresenta no sistema político migratório da maior parte dos países, repercutindo em violências diversas. Seu discurso é difundido e, sendo assimilado, agrega fatores sociais à presença de ideais exclusivos na cultura, afastando a consciência do repúdio à violência cultural na mídia. Esse mecanismo tende a privilegiar as vozes autóctones das classes mais elevadas e a renegar aquelas provindas de territórios sem destaque econômico.

Evidencia-se a ligação das abordagens de violência contra o imigrante com o colonialismo e a relação colonial do capitalismo com o mundo. Além dos domínios pelos quais o colonialismo é conhecido, este também impõe a dominação epistemológica, trazendo o saber para as relações de poder, conduzindo à supressão ou à subalternidade muitos saberes próprios de povos e nações colonizados (Santos; Meneses, 2009). Nos caminhos da colonialidade, a população do Sul é vista como gente de segunda categoria, inclusive internamente, tendo sido educada a ver sob a ótica do dominador. Esse fator se estende para a visão social sobre migrantes do Sul.

O cinema, enquanto mídia, também é um território de expressão de ideologias, sendo que as manifestações violentas da hegemonia ocupam um espaço preocupante. Entra em evidência a afirmação de Jesús Martín-Barbero (2009, p. 12): "já sabemos que a ideologia dominante é a da classe dominante, e o que a classe dominante faz é dominar do jeito que puder." A influência da classe dominante pode ser vista na percepção e nos ideais envolvendo a nação, de modo que, mesmo que a história das sociedades esteja intrinsecamente relacionada aos movimentos migratórios, nem sempre ocorre a sensibilização para a causa intercultural.

Em meio à desigualdade social e de representações, a violência estrutural e a violência cultural repercutem sobre imigrantes. Apesar de exemplos didáticos e empáticos de representações, inúmeros filmes hegemônicos apresentam os países do Sul como territórios distantes em termos de identificação, realçando uma precariedade econômica ou um conjunto de comportamentos estereotipados de seus habitantes, sem que isso seja, necessariamente, trabalhado como causa de estranhamento. As pessoas provindas dos países do Sul são, frequentemente, representadas pelo cinema hegemônico como selvagens, possuidoras de valores duvidosos, violentas ou, quando não, com exotismo ou como um espetáculo do sofrimento. Atende-se à satisfação do olhar e à propagação da repulsa. Nesses casos, a presença de tais pessoas é tida como fator de ameaça aos modos de vida, à segurança ou ao crescimento econômico, sendo vistas como causa de prejuízos no território de chegada e, portanto, elemento a ser combatido ou afastado. 
Esta pesquisa parte do interesse pela causa da interculturalidade e pelas iniciativas cinematográficas que atuem em prol da paz, nomeadamente reconhecendo o cinema intercultural. Para nos contrapor à violência que, reiteradamente, deixa marcas no cinema hegemônico, buscaremos entender como o cinema intercultural pode contribuir para desconstruir imaginários que tentam "naturalizar" a violência contra a pessoa imigrante, bem como construir novos imaginários sociais.

\section{REFERENCIAL TEÓRICO}

São encontradas na literatura muitas denominações para o cinema intercultural, das quais Hudson Moura (2010, p. 45, grifo do autor) cita: "Cinema multicultural, mestizo, pós-colonial, transnacional, híbrido, minoritário...". Trata-se de um cinema no qual as técnicas cinematográficas a respeito de temas e narrativas conhecidos são exploradas de modo original. 0 ponto de vista, como explica Moura (2010, p. 46), é distinto: "não é mais um olhar 'forasteiro' que observa uma realidade exótica, mas sim um olhar estrangeiro, vindo do interior mesmo dos cinemas nacionais."

Um aspecto importante desse cinema está nas imagens apresentadas, que, conforme Moura (2010), não se repetem no exotismo do estrangeiro ou na marginalidade ou violência habitualmente relacionadas aos imigrantes da classe popular. Sobre os cineastas:

\footnotetext{
Eles se voltam para o assunto da língua, da classe social, do trabalho e sua inserção na sociedade. 0 cinema se torna, assim, uma mídia portadora de significação para essa comunidade e um meio privilegiado de comunicação e experimentação artística. É sobretudo através de um olhar integrador, de transferência, de adaptação e de aceitação do "Outro" (sua cultura, sua língua) que eles mostram que fazem parte da sociedade e que eles devem reivindicar seus lugares. (Moura, 2010, p. 46, grifo do autor)
}

Ao contrário de determinadas abordagens que hierarquizam, omitem ou anulam as diferenças culturais (por desconhecimento, desinteresse ou insignificância conferidos à alteridade), o trato dado pelo cinema às distinções e particularidades apresenta características próprias em uma abordagem intercultural. Se o cinema é um meio de expressão que, como dito por Andréa França (2003, p. 18), é extensivo a todos, em princípio "ele não reúne as pessoas num todo homogêneo e unificado: ao contrário, ele acentua a singularidade de uma comunidade de diferentes, em que o vizinho ou parceiro é o estranho." Diante disso, a autora relata que os processos de experimentação do tempo, do espaço e do sujeito, no cinema, são chamados ao campo da ética e da responsabilidade. Como abordagens usuais não atendiam às necessidades de certos cineastas, emergem filmes que, conforme França (2003, p. 14), "criam formas de visibilidade e de sensibilidade para um estado de mundo difuso, que comporta lado a lado sujeição e formas de enfrentamento, exploração e liberdade."

"Na estética que dá forma a este cinema", discutindo o âmbito intercultural ibero-americano, Teixeira e Fischer (2016, p. 34) mencionam que "o fora de lugar e o nomadismo são potencializados, sintomática e poeticamente, na bizarra coreografia resultante de jogos imagéticos que alternam o estático e o dinâmico". Pode-se pensar nos usos do diálogo com a sociedade e com a realidade. Nesse sentido, França (2003) acha válido observar como o cinema traduz a "insegurança" global e legitimadora da violência no planeta. A autora chama atenção para o modo como esses filmes operam com o presente, em aproximação ou em distanciamento com diversos temas divulgados pelas redes mundiais: guerra, imigração, abuso dos direitos individuais, discriminação, xenofobia, desigualdades sociais, formas de vida locais, práticas políticas e culturais.

Além da relação dos filmes a partir de um fragmento de uma realidade popularmente conhecida, o cinema pode ser refletido envolvendo valores pouco abordados e com potencialidades sociais. Esse novo cinema, segundo França (2003, p. 16), tem discursado "a respeito das novas formas de viver, de pensar, das novas modalidades de trabalho, de sociabilidade, de intolerância e sujeição. Há uma outra subjetividade estética e política, um novo capital humano como sujeito do discurso 
cinematográfico." Esses filmes são atravessados por certas perguntas (França, 2003, p. 16): "que espécie de mundo é esse? Como foi que se conseguiu extirpar, de forma tão radical e violenta, qualquer princípio ético de fraternidade e compaixão num mundo que até há pouco se orgulhava de ser herdeiro das tradições iluministas e humanistas?". A autora (França, 2003) menciona que mesmo que a narrativa não aponte as respostas, elas mobilizam a interrogação e convidam o espectador a perceber esse paradoxo.

0 cinema intercultural reconhece a violência e a traz por meio do olhar de sujeitos marginalizados, de tal maneira que não seja vista como um espetáculo, excluído da reflexão propiciada pelo fundo social, cultural e emocional. Por essa e por outras razões, é um cinema difícil de ser avaliado segundo os antigos moldes: "cinema descentrado, perturbador, animado pela presença inquietante de personagens em reiterado deslocamento físico deslizando por entre cenas em que o movimento estabelece, paradoxalmente, estreita parceria com a dificuldade de fluxo" (Teixeira; Fischer, 2016, p. 35).

Mesmo não possuindo intenções de transformação, inovação, denúncia ou documento, o cinema intercultural se converte em uma declaração valiosa. França (2003) considera que mesmo que nem todos os filmes coloquem a linguagem do cinema de ação político tradicional em cheque, o cinema recente oportuniza um tipo de testemunho das imagens do mundo, com possibilidade profética e visionária. Conforme menciona a autora (França, 2003, p. 17), além de trazer à tona a "massa de excluídos-errantes", alguns desses filmes ainda promovem "a possibilidade de outros mundos e outras formas de vida, em um desejo de experimentação que inventa novas linguagens para além dos preceitos narrativos do cinema de ação convencional (causalidade, unidade espaço-temporal, desenlace etc.)".

Ao oferecer "visibilidades mais complexas, densas e paradoxais" a grupos "estereotipados e/ou marginalizados pelos meios de comunicação", esses filmes, conforme França (2003, p. 19), possuem ampla extensão política. A autora destaca as cenas apresentadas e seus efeitos:

deslocamentos contínuos, um estado de nomadismo e de estrangeiridade que faz ressoar um desejo de futuro, de novos traçados de vida, de esperança. Acredito que esses filmes [...] suscitem esteticamente um espaço de reflexão a respeito da guerra, da militarização da existência, da noção de fronteira e de território, da mídia em relação a isso. (França, 2003, p. 19, grifo da autora)

As imagens tentarão traduzir as experiências de viver entre culturas diferentes, que passam a ter novas visões de mundo. Com característica híbrida, o cinema intercultural, conforme Moura (2010, p. 47), é "colocado numa relação de força na sua forma contestatória em relação a uma estética dominante". 0 autor considera que o intercultural coloca a cultura do "outro" como passível de troca: "o intercultural é sempre e fundamentalmente concebido a partir do relacional", de modo que não pode deixar de ser um agente coletivo (Moura, 2010, p. 50).

0 diálogo intercultural também é discutido por França (2006), que aborda a construção de imaginários pelo cinema: mais do que uma reprodução histórico-econômica do planeta, o cinema constrói comunidades imaginadas, com novos sentidos de mundo, sendo capaz de constituir resistência na homogeneização. Ela explica que, atualmente, não é suficiente visibilizar um povo ou cultura que busca sua sobrevivência. 0 cinema (França, 2006, p. 398) não para de produzir e "oferecer imagens de esquecidos, desamparados, caricaturados, qualificando-os como reais"; no entanto "a circulação acelerada de imagens do mundo pelo mundo" torna "ineficaz a visibilidade pura e simples do outro". Por isso,

É necessário inventar, também através do cinema e das imagens, novas terras, novas nações, novas comunidades ali onde elas ainda nem sequer existem. Essas novas terras não são geográficas, bem entendido, são territórios afetivos, sensíveis, novos mapas de pertencimento e afiliação translocais. (França, 2006, p. 398, grifo da autora) 
ANO $15 \cdot$ NÚMERO $28 \cdot 1$ 10 SEM. $2018 \cdot$ ORGANICOM

A ATUAÇÃO DO CINEMA INTERCULTURAL NOS IMAGINÁRIOS

A importância da percepção dos sujeitos migratórios se torna mais decisiva em tempos de elevado número de migrações. Nunca se viram, conforme Moura (2010, p. 43), "tantos deslocamentos humanos quanto no século XX. A Segunda Guerra Mundial provocou uma nova experiência no movimento de populações". Moura (2010) explica que o mapa mundial foi retraçado de modo que muitas culturas se dispersaram ou foram transferidas de região.

O sistema econômico produz desigualdades em meio aos deslocamentos globais. É útil pensar, conforme França (2003), o modo como certos filmes contemporâneos enxergam a internacionalização, tendo em vista que novos protagonistas emergem em meio ao surgimento de fronteiras camufladas e sutis, visto que as fronteiras nacionais, étnicas, culturais, privadas e ideológicas se encontram em diluição. As telas contemporâneas apresentam as vítimas das desigualdades: "são os desamparados do presente. Refugiados, sobreviventes e desvalidos, imigrantes, estrangeiros em busca de melhores condições de vida, desesperados que abandonam seu cadinho de terra e suas referências culturais" (França, 2003, p. 13).

No contexto de violência, ao qual migrantes e demais sujeitos que estão à margem do progresso econômico estão submetidos, é pertinente observar o ponto de vista audiovisual com o qual cada narrativa é dirigida, visto que o cinema é também uma janela para tais sujeitos (serem vistos ou verem).

\section{METODOLOGIA}

Trata-se de revisão bibliográfica referente à migração e à internacionalização no cinema, buscando observar encontros entre o cinema intercultural e a comunicação para a paz no que tange à violência à qual migrantes estão submetidos.

\section{RESULTADOS}

0 cinema, estando sujeito ao enquadramento, possibilita a visão de um ponto de vista. Por nem sempre conseguir apresentar os encontros entre culturas em seus aspectos totais, o cinema o faz, constantemente, de forma concreta, mostrando contatos mínimos, com a possibilidade de respeitar crenças e ideologias ao manifestar os valores comuns que unem os povos e as relações afáveis entre pessoas de diferentes grupos (Martínez-Salanova, 2009). Os filmes são entendidos como um meio potente na desconstrução de estereótipos que caem sobre migrantes, favorecendo o diálogo cultural.

Se por um lado há abordagens preconceituosas sobre migrantes, narrativas de maior reflexão intercultural também devem ser discutidas. Atuando na produção de identidades e imaginários culturais, as abordagens de deslocamentos e interculturalidade impulsionam narrativas em diferentes títulos do cinema mundial, incluindo os de diretores como Wong Kar-Wai, Sofia Coppola, Hany Abu-Assad, Alejandro González Iñarritú, Med Hondo, Roger Gnoan M'Bala, Moussa Touré, Helena Taberna, Ana Torres, Pedro Pérez Rosado, Gerardo Olivares e Claire Denis. Tais temáticas também ocupam espaço no cinema brasileiro contemporâneo, continuadamente preocupado com a tentativa de captar atuais características sociais; pode-se observar essa reflexão, por exemplo, em trabalhos de Anna Muylaert, Marcelo Gomes, Larissa Figueiredo, Breno Silveira, Walter Salles, Sergio Bianchi e Karim Aïnouz.

Uma análise de alguns títulos da América Latina é feita por Brandão (2012), destacando algumas categorias de temas trabalhados, como: viagens internacionais impulsionadas por um desejo revisionista, em El viaje (Fernando Solanas, 1992), Amigomío (Alcides Chiesa e Jeanine Meerapfel, 1994), Terra estrangeira (Walter Salles e Daniela Thomas, 1996); uma vertente revisionista de retorno ao sertão brasileiro, com destaque para Baile perfumado (Lírio Ferreira e Paulo Caldas, 1997) e Central do Brasil (Walter Salles, 1998); novas discussões sobre movimentos e relações pessoais em En la puta vida(Beatriz Flores Silva, 2001), Dois perdidos numa noite suja (José Jofilly, 2003); negociações com o gênero road movie, como em Y tu mamá también(Alfonso Cuarón, 2001), Histórias 
ANO 15 • NÚMERO 28 • 1ํㅗㅌ. 2018 • ORGANICOM

mínimas (Carlos Sorín, 2002), El viaje hacia el mar (Guillermo Casanova, 2003), Família rodante (Pablo Trapero, 2004), Cinema, aspirinas e urubus(Marcelo Gomes, 2005), Árido movie (Lírio Ferreira, 2005); e a presença de mulheres na estrada, na paisagem e na passagem, comandando a viagem ou sua possibilidade de deslocamento, em Sin dejar huella(María Novaro, 2000), Um passaporte húngaro (Sandra Kogut, 2001), Tan de repente (Diego Lerman, 2002), Cleopatra (Eduardo Minogna, 2003), Solo Dios sabe (Carlos Bolado, 2006), Babel (Alejandro Gonzáles Iñárritu), O céu de Suely (Karim Ainouz, 2006) e Una novia errante (Ana Katz, 2007).

0 debate em torno das migrações, de um ponto de vista abrangente, como dito por Denise Cogo (2013), contribui para "pluralizar os imaginários e memórias sobre as migrações contemporâneas e inserir, na agenda pública, demandas relacionadas aos direitos humanos dos migrantes". A prioridade dada ao diálogo cultural é cada vez mais comum no cinema, conforme comenta MartínezSalanova (2009). Ainda que não seja tão reconhecido como era de se esperar, existe esse cinema "que obriga ao conhecimento e à reflexão ativa, que prioriza os casos de interação e contribuição mútua, que sensibiliza a novos interlocutores [...] para 0 conceito e as dimensões do diálogo intercultural" (Martínez-Salanova, 2009, p. 229, tradução nossa)

Há uma fragilidade na preocupação da abordagem da diversidade de culturas (em número, qualidade e na circulação das já existentes), especialmente se considerarmos o quanto as recentes dinâmicas sociais levam a tal necessidade. Todavia, aparentemente, o cenário tende a melhorar. Como aponta Moura:

A impressão que se tem é que cada vez mais as pessoas cruzam fronteiras e transformam suas experiências em uma poderosa herança de resistência. E as mídias são testemunhas desse fenômeno. Muitos artistas transformam os traumas do deslocamento numa importante renovação do pensamento e de reflexão sobre a sociedade contemporânea. (Moura, 2010, p. 43)

Em suas características, o cinema influi até mesmo nas percepções de pertencimento. Como considerado por Appadurai (1997), é necessário que se pense além da nação. Essa necessidade deve receber uma preocupação, especialmente nesse contexto de dimensão de territorialidade que tem a nação moderna. Reconhecendo que nação é algo imaginado, o autor considera que é a imaginação que leva além da nação. Conforme escreveu Appadurai (1997, p. 34, grifo do autor), "o movimento humano no contexto de crise do Estado-nação reforça a emergência de translocalidades".

Dialogando com a formação de imaginários está a abertura para gerar imagens de futuro. Sendo uma forma de arte, o cinema, conforme França (2006), mais do que representar um estado de coisas, pode fornecer uma imagem da realidade por vir, sendo uma abertura para um mundo possível, com outros imaginários de terras e fronteiras.

A força do imaginário, também abordada na comunicação para a paz, é reconhecida no cinema intercultural, possibilitando um espaço para a solidariedade. França (2003, p. 26) menciona ser possível entender a imagem de terras e fronteiras, produzida e experimentada nos filmes, como inspiradora de "uma legitimidade emocional profunda, identificações imaginárias, estimulando solidariedades transnacionais, produzidas pelas diferentes formas de espacialidade, temporalidade, movimento, ritmo e textura, próprias aos filmes em questão".

Como nem sempre ocorrem adequadas abordagens por meio do conteúdo da mídia hegemônica, a comunicação alternativa, por vezes, encara a importância do comprometimento. As redes globais provam que mesmo que a cultura dominante possua todos os meios para se difundir e impor sua voz, produtos culturais alternativos podem ser gerados. Com o exemplo do cinema, Martínez-Salanova (2009) aponta que mesmo países economicamente empobrecidos, com culturas desconhecidas no Ocidente, podem ser visibilizados internacionalmente, expondo visões locais e apresentando "uma grande diversidade de culturas, etnias, ideias, filosofias, comportamentos e religiões” (Martínez-Salanova, 2009, p. 225, tradução nossa). 
Com a visibilização mais próxima de localidades e de populações (em termos narrativos e de produção), pensamentos, modos de vida e identidades também passam a ser vistos de maneira mais próxima. 0 cinema ocidental produziu conhecidos filmes que, como lembra Martínez-Salanova (2009), representam a força de armas, a imposição cultural e a derrota do outro, que são empregadas para dissipar o conflito e impulsionar a civilização ou a política imperialista, acarretando, por exemplo, o desaparecimento das culturas indígenas. Vale a observação de que tal fato constitui um exemplo da representação da violência no cinema empregada de modo a fortalecer argumentos da violência estrutural e da violência direta.

Os filmes abordados no parágrafo anterior refletem mais do que o interesse de registro, pois, longe de constituir um relato histórico neutro ou comprometido com as vítimas, por vezes, os opressores são enaltecidos na dramatização. Apesar da violência entre culturas apresentada no cinema, há filmes que - como aponta Martínez-Salanova (2009) - provocam perguntas sobre 0 porquê de a convivência pacífica se converter em disputa, e há filmes que exaltam a coexistência entre religiões e etnias, sendo interessante notar que "são os países pobres os que mais adequadamente reproduzem a necessidade da convivência cultural" (Martínez-Salanova, 2009, p. 226, tradução nossa, grifo nosso).

Espera-se que as atuais facilidades propiciadas pelas novas tecnologias de produção animem centros educativos e professores para a promoção da realização de produtos audiovisuais e telemáticos, levando diferentes pessoas a criar, planejar, investigar e produzir (Martínez-Salanova, 2009). Diante da diversidade cultural dos interlocutores, será necessário promover "alianças e dinâmicas que ajudem a formar redes locais que se oponham à exclusão das minorias, em resposta ao poder e à força dos enquadramentos sociais e culturais dominantes" (Martínez-Salanova, 2009, p. 230, tradução nossa). Nota-se, portanto, que o espaço para vozes de diferentes culturas no cinema, em relação intercultural, tende a promover o convívio pacífico entre povos, pois a mídia representa um território político que repercute na sociedade.

\section{DISCUSSÃO E CONCLUSÕES}

Assim como é influenciada por grupos da sociedade, especialmente pelos detentores do poder de voz, a mídia exerce influência social, incluindo interferência sobre a formação de imaginários identitários e de ideais de vida. Por vezes, ela reforça uma atenção centrada no território ou na nação a que pertence e mantém características colonialistas, promovendo exclusões.

Além da questão particular da imigração, que torna os imigrantes um grupo socialmente vulnerável, há um despreparo, nos territórios de acolhida, quanto à diversidade (cultural, étnica, social). Impressões relacionadas a esses estranhamentos são expressas, no cinema, a partir das interpretações dos realizadores que, por vezes, se aliam aos interesses de grupos dominantes, em meio aos preconceitos relacionados ao "outro". Constitui um desafio modificar as maneiras de perceber identidades e alteridades, fortalecendo a lógica do global na comunicação.

0 cinema é uma mídia que permite a veiculação da representação de realidades e a exploração de imaginários. Cumpre um papel que deve ser aproveitado, otimizado e expandido. A busca por inclusão social - que contrasta com abordagens violentas, envolvendo a submissão de grupos socioacêntricos - se relaciona à comunicação e encontra, no cinema, um território de exploração de potencialidades comunicativas, artísticas e de articulação social. Associam-se a tais interesses as estratégias da comunicação para a cultura de paz e a interculturalidade, com amplo potencial de inclusão, respeito e participação social de migrantes e demais grupos estigmatizados. Assim, o cinema intercultural está atrelado aos objetivos da comunicação para a paz, apresentando conteúdos que permitem a sensibilização do olhar e que apontam para novas possibilidades de vivência.

Entende-se que o cinema intercultural participa da quebra da imagem pejorativa que a pessoa migrante costuma receber em abordagens superficiais, combatendo um contexto de violência cultural, com técnicas que se aproximem de uma cultura 
ANO 15 • NÚMERO 28 • 1오. SEM. 2018 - ORGANICOM

A ATUAÇÃO DO CINEMA INTERCULTURAL NOS IMAGINÁRIOS

de paz. Assim, com novas e eficientes estratégias de democratização e de abordagem cidadã que possibilitam a interação entre povos, o cinema intercultural, em seu potencial de difusão da diversidade cultural e de promoção do diálogo, contribui para a transformação social.

Um dos pontos de destaque do cinema intercultural está no espaço dado às vozes não hegemônicas, rotineiramente, por vozes não hegemônicas ou, ao menos, engajadas. Esse fator de contribuição democrática coopera para que preconceitos e estereótipos não sejam produzidos ou reiterados nas narrativas interculturais e para que, ao contrário, as subjetividades de populações de regiões economicamente empobrecidas, ou de outros grupos socialmente vulneráveis, sejam representadas na tela.

As melhorias das comunicações favorecem grupos excluídos (a maior parcela da população) no ato de participar da construção de um novo espaço público. Espera-se que tais grupos tenham a oportunidade de realizar uma prática comunicacional efetiva, expondo percepção, sensação e imaginação, oferecendo à sociedade novos pontos de vista sobre distintos assuntos, como pode ser visto no cinema realizado por imigrantes ou por seus descendentes próximos. As iniciativas já existentes devem ser fortalecidas e usadas como inspiração.

A comunicação precisa assumir e oferecer uma perspectiva comprometida com a paz e, assim, com a diversidade. 0 cinema intercultural, mesmo sendo um campo à parte dos estudos para a paz, possui princípios comuns com estes ao expor inadequadas representações da violência e ao possibilitar a reflexão e a empatia envolvendo culturas a partir das violências retratadas. Despertando para as diferentes formas de paz, a caminho da paz cultural, a comunicação para a paz apresenta o enorme potencial transformador de uma abordagem comprometida com grupos "periféricos", em sintonia com a cidadania global.

\section{REFERÊNCIAS}

APPADURAI, Arjun. Soberania sem territorialidade: notas para uma geografia pós-nacional. Revista Novos Estudos Cebrap, São Paulo, v. 3, n. 49, p. 33-46, 1997.

BRANDÃO, Alessandra Soares. Viagens, passagens, errâncias: notas sobre certo cinema latino-americano na virada do século XXI. Rebeca, v. 1, n. 1, p. 72-98, 2012. Disponível em: <https://bit.ly/2A6yNqX>. Acesso em: 19 abr. 2018.

COGO, Denise. Fluxos migratórios globais. A busca de trabalho e fuga da pobreza. Entrevista especial com Denise Cogo. Revista Instituto Humanitas Unisinos On-line, São Leopoldo, 13 abr. 2013. Disponível em: <https://bit.ly/217004r>. Acesso em: 27 mar. 2018.

DISKIN, Lia. Introdução à cultura de paz. In: REDE Ação Pela Paz. Guia de cultura de paz. São Paulo: Secretaria do Verde e do Meio Ambiente, 2007. p. 6-11.

FRANÇA, Andréa. Cinema de terras e fronteiras. In: MASCARELLO, Fernando (Org.). História do cinema mundial. Campinas: Papirus, 2006. p. 395-412.

Terras e fronteiras no cinema político contemporâneo. Rio de Janeiro: 7Letras, 2003.

GALTUNG, Johan. Três formas de violência, três formas de paz. A paz, a guerra e a formação social indo-europeia. Revista Crítica de Ciências Sociais, Coimbra, v. 71, p. 63-75, 2005. Disponível em: <https://bit.ly/2I9KSya>. Acesso em: 15 dez. 2017. 
MARTíN-BARBERO, Jesús. As formas mestiças da mídia. Entrevistadora: Mariluce Moura. Revista Pesquisa Fapesp, São Paulo, n. 163, p. 10-15, 2009.

MARTÍNEZ-SALANOVA, Enrique. Medios de comunicación y encuentro de culturas: propuesta para la convivencia. Comunicar, Huelva, v. 16, n. 32, p. 223-230, 2009. Disponível em: <https://bit.ly/2HSXMBy>. Acesso em: 20 dez. 2017.

MOURA, Hudson. 0 cinema intercultural na era da globalização. In: FRANÇA, Andréa; LOPES, Denilson (Org.). Cinema, globalização e interculturalidade. Chapecó: Argos, 2010. p. 43-66.

SANTOS, Boaventura de Sousa; MENESES, Maria Paula. Introdução. In: (Org.). Epistemologias do Sul. Coimbra: Almedina, 2009. p. 9-19.

TEIXEIRA, Rafael Tassi; FISCHER, Sandra. Cinema intercultural ibero-americano: estesias diaspóricas, nomadismos identitários, fronteiras em trânsito. In: CARDOSO, João Batista Freitas; SANTOS, Roberto Elísio dos (Orgs.). Miradas sobre o cinema iberoamericano contemporâneo. São Caetano do Sul: USCS, 2016. p. 15-36.

Texto recebido em 08.04.2018 e aprovado em 27.05.2018. 